\title{
Human Capital Inequality, Life Expectancy and Economic Growth ${ }^{*}$
}

\author{
Amparo Castelló-Climent ${ }^{a}$ and Rafael Doménech ${ }^{b}$ \\ a Universidad Jaume I \\ $b$ Universidad de Valencia
}

June, 2002.

\begin{abstract}
This paper provides a theoretical model in which inequality affects per capita income when individuals decide to accumulate human capital depending on their life expectancy. The model assumes that life expectancy depends to a large extent on the environment in which individuals grow up, in particular, on the human capital of their parents. After calibrating the life expectancy function according to the international evidence for cross-section data, our results show the existence of multiple steady states depending on the initial distribution of education. In particular, human capital may converge towards different stable steady states. In accordance with the evidence displayed by many developing countries, the low steady state is a poverty trap in which children are raised in poor families, have a low life expectancy and work as non-educated workers all their lives.
\end{abstract}

Keywords: Life expectancy, human capital, inequality.

JEL Classification: O11, O40.

\section{Introduction}

Since the last decade there has appeared an increasing body of literature that analyzes the influence that inequality in the distribution of income or wealth may exert on economic growth and income differentials across countries. The complexity of the relationship between inequality and growth has led theoretical models to look at this problem in different ways. Broadly, the literature has focused on two mechanisms through which inequality may influence growth. ${ }^{2}$ The first mechanism can be called the fiscal policy

* R. Doménech gratefully acknowledges the financial support of CICYT grant SEC99-0820. Address for comments: Amparo Castelló Climent, Universidad Jaume I, 12071 Castellón, Spain. e-mail: acastell@eco.uji.es and rafael.domenech@uv.es.

2 Benabou (1996) or Aghion, Caroli and García-Peñalosa (1999) survey this literature. 
approach and has been analyzed by Bertola (1993), Alesina and Rodrik (1994) or Persson and Tabellini (1994), among others. The main idea behind these models is that, in the political process, economies with greater inequality in the distribution of wealth will vote for greater redistributive policies than those with a more even distribution. If such redistributive policies are financed with distortionary taxes affecting human and physical capital accumulation rates, the more unequal societies will experience lower growth rates. The second kind of models have the common assumption of incomplete credit markets, an approach started with the pioneer model of Galor and Zeira (1993). ${ }^{3}$ In this model, the assumption of non-convexities in the accumulation of human capital jointly with imperfect credit markets means that individuals who inherit an amount lower than a threshold level do not invest in human capital and work as unskilled workers. Therefore, in this model initial distribution of wealth is crucial in determining the long-term human capital and income levels, since the higher the number of individuals below the threshold level, the lower the average accumulation rate of the economy.

This paper explores an alternative channel through which inequality in the distribution of human capital may influence the process of human capital accumulation. This new mechanism is based on the relationship between human capital distribution, life expectancy and the accumulation of human capital.

Some models that have analyzed the relationship between demography and development have noticed the important role played by life expectancy in determining the optimal education decisions of individuals. For example, Ehrlich and Lui (1991) focus on a theoretical model that links longevity, fertility and economic growth to explain the "demographic transition". In their overlapping generation model, a sufficient exogenous increase in longevity promotes economic growth as well as reduces fertility rates. In a similar model, Blackburn and Cipriani (2002) endogenize life expectancy. As a result, their model generates multiple development regimes depending on initial conditions. Endogenizing life expectancy allows Blackburn and Cipriani (2002) to explain jointly the main changes that take place during the demographic transition of economies, such as greater life expectancy, higher levels of education, lower fertility and later timing of births. ${ }^{4}$

3 Models that relate distribution and growth under the presence of imperfect credit markets include Banerjee and Newman (1993), Aghion and Bolton (1997) or Piketty (1997).

4 De la Croix and Licandro (1999) and Kalmeli-Ozcan, Ryder and Weil (2000), among others, have developed continuous time overlapping generations models in which optimal schooling investment decisions depend positively on life expectancy. In addition, the important role that life expectancy can play in models with endogenous fertility rates and human capital investment decisions is also revealed in the recent papers of Kalemli-Ozcan (2001), Soares (2001) and Tamura (2002). 
The main purpose of this paper is to include endogenous life expectancy in a model populated by heterogeneous agents. In our model individuals live for two periods and differ in their second period survival probability. In particular, we consider that life expectancy is conditioned by the human capital of the families which individuals are born into, an assumption supported by the empirical evidence (see, among others, Case, Lubostky and Paxon, 2001). Given their expected survival probabilities, individuals choose the optimal time devoted to becoming educated in order to maximize their intertemporal utility.

The survival probability function is calibrated according to the data and, as a result, the model shows multiple steady states. ${ }^{5}$ In particular, the time individuals devote to human capital accumulation converges towards two steady states: poor individuals converge to a low steady state and rich individual converge to a high steady state. Consequently, the initial distribution of wealth determines the long-term average human capital and the average income in the economy. The fewer the number of individuals with education lower than a threshold level, the greater the average human capital and average income in the economy.

Although the policy implications we obtain are similar to those of Galor and Zeira (1993), the underlying assumptions of the models are quite different. In their model the assumptions of imperfect credit markets and indivisibilities in human capital investment are crucial for the results. In our model, the results are mainly due to the assumption of differences in the survival probabilities among individuals. Hence, in Galor and Zeira (1993) model, poor individuals would invest more human capital if capital markets were perfect. In our model, even with perfect capital markets, poor individuals invest a low amount of human capital since their low life expectancy increases their opportunity cost of becoming educated.

The structure of the paper is as follows. Section 2 displays the basic structure of the model. Section 3 calibrates the model and analyses the relation between inequality and growth. Finally, Section 4 presents the conclusions reached.

\section{The model}

In this section we present a very simple model to analyze the relationship between in-

5 Other models with heterogeneous agents that generate multiple steady states, without assuming non-convexities in the production process, are the recent papers of Moav (2001) or Eicher and García-Peñalosa (2001). In Moav (2001), parents face a trade-off between child quality and child quantity. The endogenous fertility choice in this model results in multiple steady states. In Eicher and García-Peñalosa (2001), the key assumption for the existence of multiple steady states is the interdependence of supply and demand for skilled workers under skilled-biased technological change. Azariadis (2001) offers an excellent survey on the literature about poverty traps. 
equality, life expectancy and growth. For this purpose we consider an overlapping generation model in which individuals can live at most for two periods. The probability of living during the whole first period is one, whereas the probability of living until the end of the second period is $\pi_{t+1}$. At the end of the first period each individual gives birth to another such that all individuals have a descendent. In every period the economy produces a single good that is used for consumption.

\subsection{Life expectancy}

The economy is populated by individuals that differ in their family wealth but that are identical in their preferences and innate abilities. We assume that an individual's life expectancy will depend on the economic status of the family which the individual is born into.

The empirical evidence shows a negative association between socioeconomic status and mortality. Marmot et al. (1991) found in the Whitehall II study a positive association between the grade of employment of British civil servants and their health status, a result already obtained in the first Whitehall study initiated in 1967. More recently, using data for the United States, Deaton and Paxon (1999) have found that higher income is associated with lower mortality, whereas Lleras-Muney (2002) findings reveal that education has a large negative causal effect on mortality.

Some papers have also suggested that this relation is not linear. Smith (1999) analyses the relation between individuals' health and their income or wealth using the Health and Retirement Survey (HRS) for 12,000 American individuals. He estimates an order probit model with self reported health status as the dependent variable. ${ }^{6}$ The results show that the relationship between self reported health and income or wealth is non-linear, and that the positive and statistically significant effect of income and wealth on self reported health status decreases as socioeconomic status increases.

However, Case, Lubotsky and Paxon (2001) suggest that the gradient, that is, the positive association between health and socioeconomic status, has its origins in childhood. They provide evidence of a positive relationship between household income and child health. Likewise, Currie and Hyson (1999) find that being born into low socioeconomic status family increases the probability of reporting poor health at age 23 and 33 . Other studies also show that parents' education has a positive impact on child height, which may be used as an indicator of long-run health status, even after controlling for parents' income (see, for example, Thomas, Strauss and Henriques, 1990 and 1991).

On this matter, there are medical studies that point out the important role that the environment plays during pregnancy and on newborn children in determining the fu-

6 Smith, Taylor and Sloan (2001), using the HRS, find that subjective perceptions of mortality are good predictors of observed mortality. 
ture diseases and illnesses which an individual may suffer from. For example, Ravelli et al. (1998) investigate glucose tolerance in people born around the time of famine in the Netherlands during 1944-1945. They found that prenatal exposure to famine, mainly during late gestation, was associated to decreased glucose tolerance in adults increasing the risk of diabetes. Barker (1997) focuses on the "fetal origins" hypothesis which states that human fetuses change their physiology and metabolisms in order to adapt to a limited supply of nutrients. These programmed changes may be the origins of a number of diseases in later life such as hypertension, coronary heart disease, strokes and diabetes.

The foregoing results suggest that it is realistic to assume that individuals born into rich families will have higher life expectancy than those born into poor families, who are more likely to be affected by undernourishment during early stages of life and an unhealthier environment during childhood, for instance, lower standards of hygiene at home, an unhealthier diet or less use of preventive and curative medical services. Moreover, we consider that the positive effect that family income may exert on an individual life expectancy decreases as income increases and vanishes at high income levels. In particular, as human capital is one of the main determinants of income and wealth, we assume that parents' human capital will determine the survival probability of their children. Thus, we consider a positive but decreasing effect of parents' human capital on the life expectancy of their descendants. The probability of an individual $i$ born in period $t$ surviving to different periods $(t+n)$ is as follows:

$$
\pi_{i t+n}^{t}=\left\{\begin{array}{ll}
1 & \text { for } n=0 \\
\pi_{i t+1}^{t}\left(h_{i t}^{t-1}\right) & \text { for } n=1 \\
0 & \text { for } n \geq 2
\end{array}\right\}
$$

where $h_{i t}^{t-1}$ is the human capital of the parent. In the next section we use a specific equation for the survival probability according to the empirical evidence of the relationship between life expectancy and schooling years. Given that the evidence is only available for schooling years, throughout the paper we make the survival probability depend on parents' schooling years instead of a broad concept of human capital.

\subsection{Technology}

In the first period of life individuals are endowed with one unit of time. They allocate $L_{t}^{i}$ units towards producing final goods with the following technology:

$$
y_{i t}^{t}=A L_{i t}^{t}
$$

where $A$ is a function of the level of technology and other production inputs and $0 \leq$ $L_{i t}^{t} \leq 1$. For simplicity, we consider that $A$ is constant.

Individuals allocate the remaining units of their time $\left(1-L_{t}^{i}\right)$ towards acquiring 
formal education for the second period according to the function:

$$
h_{i t+1}^{t}=\theta\left(1-L_{i t}^{t}\right)
$$

where $\theta$ is the number of years of the first period and $h_{i t+1}^{t}$ the schooling years that individual $i$ accumulates when young.

In the second period of life, individuals allocate all their time endowment to the production sector such that,

$$
y_{i t+1}^{t}=A L_{i t+1}^{t} e^{\alpha h_{i t+1}^{t}}
$$

where $L_{i t+1}^{t}=1$. Thus, the higher the human capital stock accumulated during the first period the higher the income produced in the second period. The specification of the production function in the second period relies on the work of Mincer (1974), since it relates the log of income to schooling years

$$
\ln y_{i t+1}^{t}=\ln A+\alpha h_{i t+1}^{t}
$$

Therefore, the coefficient $\alpha$ can be interpreted as the return of education.

\subsection{Preferences}

The preferences of an individual born in $t$ are represented by a log-linear utility function of the form:

$$
u_{i}^{t}=\ln c_{i t}^{t}+\gamma \pi_{i t+1}^{t}\left(h_{i t}^{t-1}\right) \ln c_{i t+1}^{t}
$$

The expected lifetime utility is defined over consumption when young $\left(c_{i t}^{t}\right)$ and consumption when old $\left(c_{i t+1}^{t}\right)$, where the second period utility is discounted for the endogenous survival probability $\pi_{i t+1}^{t}\left(h_{i t}^{t-1}\right)$ and for the rate of time preference $\rho$, where $\gamma=1 /(1+\rho)$.

During the first period, agents can finance their consumption with two types of income. The first one is given by the production of goods $\left(y_{i t}^{t}\right)$ which, as equation (2) states, is a function of the time devoted to production. During the time they invest in education, we assume they have access to a minimum income per schooling year. Thus, the level of consumption in $t$ is given by

$$
c_{i t}^{t}=y_{i t}^{t}+\beta A\left(1-L_{i t}^{t}\right)
$$

where $\beta$ is a parameter, such that $0 \leq \beta \leq 1$, which determines the revenue that covers the consumption while this agent is attending school, net of all education cost. For simplicity, we assume that $\beta$ is exogenous and that this revenue increases with $A$, that is, consumption during education years is higher in economies with higher A. In most 
economies, the revenue financing consumption whereas attending to school, which is thus proportional to $\left(1-L_{i t}^{t}\right)$, is jointly financed by parents and public policies such as grants. Theoretical models usually incorporate bequests as a basic resource for financing education years. However, as long as bequests are a function of parents' incomes, this constitutes an important channel through which the human capital of parents affects the human capital of their descendants. Since we are interested in analyzing these effects exclusively through the endogenous life expectancy, it is convenient to assume that individuals can substitute intertemporally some income, proportional to the time they invest in education but independent from the schooling years of their parents. Thus, if $\beta=0$ the intertemporal substitution of income for education is not allowed and welfare during the first period is entirely determined by $y_{i t}^{t}$.

In the second period, total income is used to finance private consumption and to pay back the income consumed during the education years of the first period:

$$
c_{i t+1}^{t}=y_{i t+1}^{t}-\frac{\beta A}{\pi_{i t+1}^{t}\left(h_{i t}^{t-1}\right)}\left(1-L_{i t}^{t}\right)
$$

For simplicity, we are assuming that the intertemporal substitution of income, which is only allowed for education, occurs at no cost. However, equation (8) takes into account the fact that individuals may not live the whole second period. As $\beta A\left(1-L_{i t}^{t}\right)$ appears in equation (8) divided by the endogenous survival probability, agents pay back all this income independently of the number of years they live in the second period.

As we show below, agents with no probability of living during the second period, because the human capital of their parents is so low, will not allocate any fraction of their time to acquiring education. At the other extreme, if $\pi_{i t+1}^{t}\left(h_{i t}^{t-1}\right)=1$, then $\left(1-L_{i t}^{t}\right)$ will reach its maximum value. In other word, the time individuals devote to education will be a function of the schooling years of their parents, but exclusively through the endogenous life expectancy since intergenerational transfers are nonexistent.

\subsection{Optimal education years}

The optimal behavior of agents is to choose the amount of human capital that maximizes their intertemporal utility function. Thus, individual $i$ chooses the time devoted to schooling $\left(1-L_{i t}^{t}\right)$ that maximizes (6) subject to the production functions (2) and (4), the accumulation of human capital (3), the budget restrictions (7) and (8), and the non negativity and inequality restrictions $\left(0 \leq L_{i t}^{t} \leq 1\right)$.

For $0 \leq L_{i t}^{t} \leq 1$, the first order condition for this problem gives place to a nonlinear function of $L_{i t}^{t}$ in terms of $h_{i t}^{t-1}$ and the different parameters of the model (see 
Appendix 1):

$$
\begin{aligned}
& (1-\beta)\left(\exp \left\{\alpha \theta\left(1-L_{i t}^{t}\right)\right\}-\frac{\beta}{\pi_{i t+1}^{t}\left(h_{i t}^{t-1}\right)}\left(1-L_{i t}^{t}\right)\right)=\gamma \pi_{i t+1}^{t}\left(h_{i t}^{t-1}\right) \\
& \left(\alpha \theta \exp \left\{\alpha \theta\left(1-L_{i t}^{t}\right)\right\}-\frac{\beta}{\pi_{i t+1}^{t}\left(h_{i t}^{t-1}\right)}\right)\left(L_{i t}^{t}+\beta\left(1-L_{i t}^{t}\right)\right)
\end{aligned}
$$

As we show below, the time individuals devote to accumulating human capital increases with their second period survival probability, which is a function of parents' human capital. Since the income in the second period depends on the time agents devote to accumulating human capital, the longer they expect to live the greater their human capital investment.

\section{Inequality and Growth}

In this section we analyze the relationship between inequality in the distribution of education, life expectancy, human capital accumulation and per capita income. Firstly, we calibrate the model. Then, we display the numerical results of the evolution of human capital over time. Finally, we explore how inequality may affect life expectancy, human capital and growth.

\subsection{Calibration}

To analyze the influence that inequality in the distribution of human capital exerts on the process of development, following Blackburn and Cipriani (2002), we assume a specific function for the second period survival probability:

$$
\pi_{i t+1}^{t}\left(h_{i t}^{t-1}\right)=\frac{\frac{\pi}{+}+\bar{\pi} \varpi\left(h_{i t}^{t-1}\right)^{\phi}}{1+\varpi\left(h_{i t}^{t-1}\right)^{\phi}} \quad \text { with } \varpi \text { and } \phi>0
$$

We choose this function due to its good properties. Thus, it is an increasing function of human capital

$$
\frac{\partial \pi_{i t+1}^{t}\left(h_{i t}^{t-1}\right)}{\partial h_{i t}^{t-1}}>0
$$

and it is bounded by $\underline{\pi}$ and $\bar{\pi}$ since

$$
\pi_{i t+1}^{t}(0)=\underline{\pi}
$$

$-8-$ 
and

$$
\lim _{h \rightarrow \infty} \pi_{i t+1}^{t}\left(h_{i t}^{t-1}\right)=\bar{\pi} \leq 1
$$

Apart from its theoretical properties, at the empirical level this function captures very well the relationship between life expectancy and human capital across countries, for appropriate values of its parameters. We rely on aggregate data since micro data relating parents' education with offspring life expectancy for a broad number of countries are not available. Figure 1 shows the dispersion between life expectancy at birth in 1985, taken from the World Bank, and the average schooling years for the population 25 years old and over in 1960, from Barro and Lee (2001). The different reference years for these two variables try to capture our assumption that the survival probability in $t+1$ of the generation born in $t$ is a function of the human capital of generation born in $t-1 .^{7}$ This figure shows a clear concave relationship between the stock of human capital and life expectancy. ${ }^{8}$ The fitted function in Figure 1 is obtained assuming that $\theta=40, \underline{\pi}=0$, $\bar{\pi}=1.0, \varpi=0.5$ and $\phi=1.4$. Given these parameters, agents have a life expectancy of 40 years if their parents have no schooling. Since the model considers two equal periods we assume a duration of 40 years for every period.

With regard to the production function a reasonable value for $\alpha$ is 0.07 , since its estimated values usually range from 0.05 to 0.15 depending on the sample (see Krueger and Lindahl, 2001). We also assume a standard value for the rate of time preference, $\rho$, equal to 0.02 , which gives a value of 0.4529 for $\gamma$, since $\theta=40$. Finally, $\beta$ is calibrated to 0.18 , in order to obtain a high steady state in which the years of education are equal to 16 , that is, the average of the maximum number of years of formal education in OECD countries (see De la Fuente and Doménech, 2001). With these parameter values the model is capable of generating multiple steady states. Nevertheless, we also explore how the changes in these parameters affect the properties of the model.

\subsection{The evolution of human capital}

Equation (9) summarizes the dynamics of the model across generations and it is repre-

7 Life expectancy at birth is defined as the number of years a newborn infant would live if prevailing patterns of mortality at the time of birth were to remain the same throughout its life. Since life expectancy has been increasing almost during recent decades, the prevailing patterns of mortality in 1960 changed in 1970 and so on. Therefore, life expectancy in 1985 also proxies the mortality patterns in 1985 of people born before this year.

8 The concave shape holds with the different available years in the sample. In addition, infant mortality relates negatively at a decreasing rate with the stock of human capital. The relationship between infant mortality and the stock of human capital may proxy the relationship between the survival probability of one generation and the stock of human capital of the previous one.

$-9-$ 


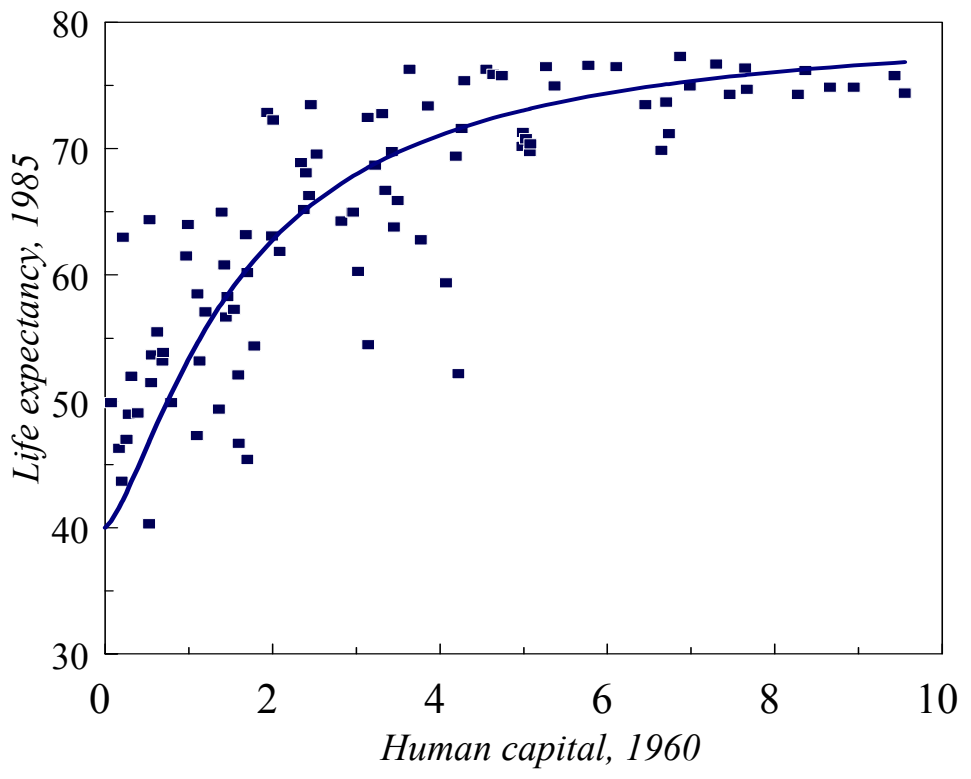

Figure 1: Life expectancy in 1985 versus average years of schooling in 1960, 92 countries.

sented in Figure 2, given the values of the parameters discussed above and the properties of the first order condition (see Appendix 2). As we can observe, the number of years devoted to the education increases with the human capital of the parents, except for low values of $h_{i t}^{t-1}$ where $h_{i t+1}^{t}$ is equal to zero. The economy exhibits three different steady states: there are two low steady states with values of zero and around 3.5 years of schooling, and a high steady state of 16 years of schooling. However, since $h_{i t}^{t-1}=h_{i t+1}^{t}=3.5$ is not a stable steady state, the dynamics of the model involve that individuals with parents having less than 3.5 years of education (that is, primary education not completed) will converge to the lowest steady state with no schooling. ${ }^{9}$

9 Some empirical papers give evidence in favour of multiple steady states models. For example, Quah (1993a, b, 1996) uses annual transitional matrix methodology to estimate long-run tendencies of incomes across countries. His findings suggest a polarization, instead of convergence, across the world incomes. Kremer et al. (2001) estimate transition probabilities over five-year intervals rather than annual intervals. Their resulting ergodic distribution gives a mass of 72 per cent of countries in the richest income category. However, they obtain that the transition to this steady state is very slow. In addition, if recent trends in international income mobility continue, their results predict an increase in the coefficient of polarization and the standard deviation of log income over the years. 


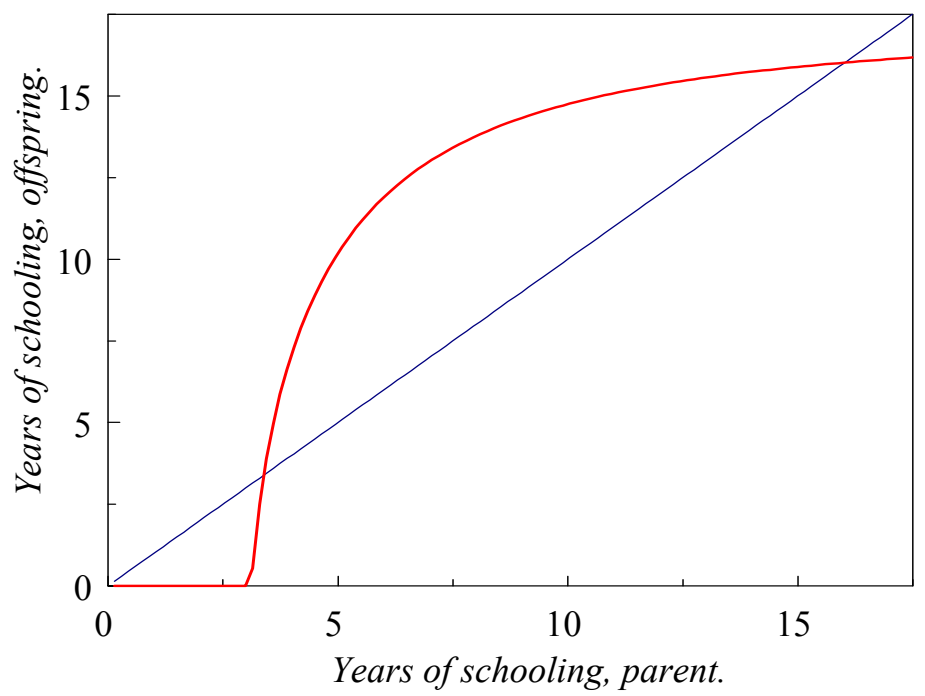

Figure 2: Human capital dynamics.

In Figure 3 we present the sensitivity of human capital steady states to changes in the different parameters of our model. As expected, an increase in the revenues to finance consumption in the first period (i.e., an increase in $\beta$ ) results in an upward shift of the function relating human capital of the two generations. It can be shown that, given the calibrated values of the other parameters, when $\beta=0$ the model exhibits only one steady state in which $h_{i t}^{t-1}=h_{i t+1}^{t}=0$, which can be interpreted as a credit market restriction for the whole economy. Our model can be seen as a generalization of Galor and Zeira's (1993) one when $\beta$ is allowed to vary among individuals. For example, individuals born into poor families with no education have no collateral and are restricted in the credit market, in a situation which is equivalent to $\beta=0$. However, in our model even if $\beta>0$ poor individuals do not invest in education because their low life expectancy increases their opportunity cost of becoming educated. Therefore, the model predicts multiple steady states even when the intertemporal substitution of income is possible.

An increase in the returns of education or in the life horizon ( $\alpha$ and $\theta$, respectively) and a reduction of the rate of time preference $(\rho)$ also produces an upward shift of the function since the investment in education is more profitable. Finally, an increase of the survival probability for any given level of $h_{i t}^{t-1}$, through higher $\phi$ or $\omega$, creates more 
education incentives.

Figure 2 makes clear that individuals who are born into poor families with low levels of education $\left(h_{i t}^{t-1} \simeq 0\right)$ will have a low survival probability $\left(\pi_{t+1}^{i}\left(h_{i t}^{t-1}\right) \simeq 0\right)$ and, therefore, have no incentives to accumulate human capital $\left(h_{i t+1}^{t} \simeq 0\right)$, devoting all their time to working in the production sector $\left(L_{t}^{i}=1\right)$, with a low productivity. This low steady state is found in some Latin American, African or South Asian countries, in which many children born into poor families, with no education, live for a short period of life, have no access to education and work as unskilled workers from childhood, affecting a large share of the world population. Using Barro and Lee (2001) data for 2000, at least 20 per cent of the population 15 years old and over was illiterate in 50 of the 108 countries in the sample. In 25 of these countries, at least 40 per cent of the population was illiterate. The share of the population with no education is 80 percent in Mali and Niger, where the life expectancy at birth is 43 and 46 years, respectively.

The dynamics of the model predict that governments could bring these families out of the no schooling poverty trap if they guarantee access to a minimum level of education for some generations and increase life expectancy.

\subsection{Human capital distribution, life expectancy and economic growth}

In accordance with the previous results, in this model the initial distribution of wealth will determine the long-run average human capital and average income in the economy. Given the simplifying assumptions we have made the model does not exhibit endogenous growth in the steady states, but it is useful to explain one source of the per capita income differentials across countries. Thus, the fewer the number of individuals with education lower than the threshold level, the greater the average human capital and average income in the economy.

Under the assumption of imperfect credit markets and indivisibilities in human capital investment, Galor and Zeira (1993) obtain similar results. In their model the initial distribution of wealth determines the share of the population with no education that works as unskilled workers. Likewise, their model also shows the possibility of two steady states, a low steady state with unskilled workers and a high one with skilled workers. However, the underlying assumptions of their models are quite different to ours. In Galor and Zeira's model, the assumption of imperfect credit markets causes that the distribution of wealth influences economic activity in the short term, and indivisibilities in human capital investment are crucial in order to preserve these results in the long run. In contrast, the results of our model are mainly due to the assumption that differences in the survival probabilities among individuals are a function of their parents' human capital.

The existence of multiple steady states depending on initial conditions makes clear 

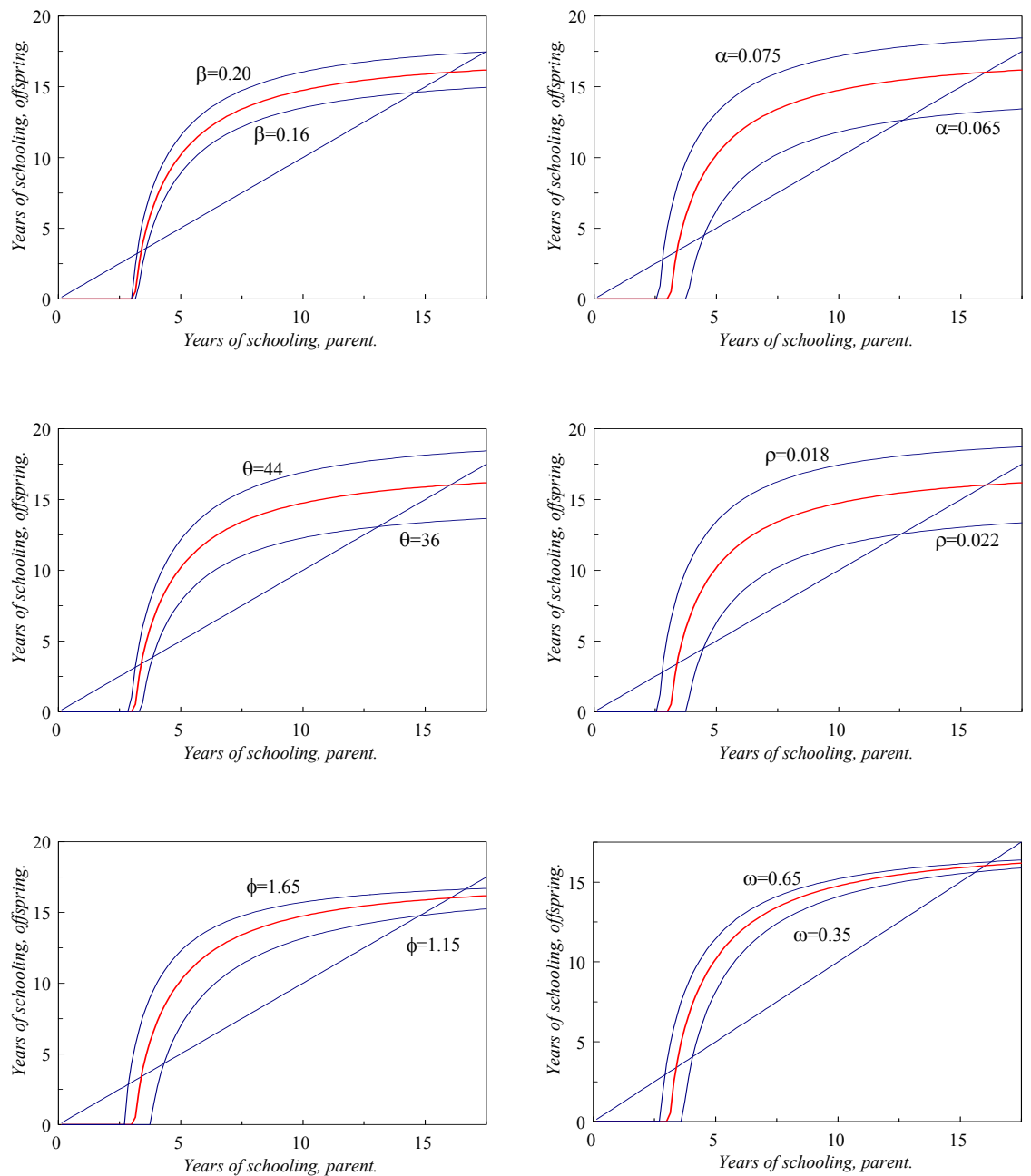

Figure 3: Sensitivity analysis of human capital steady states to changes in the benchmark values of $\beta$ (0.18), $\alpha(0.07), \theta(40), \rho(0.02), \phi(1.4)$ and $\omega(0.5)$. 


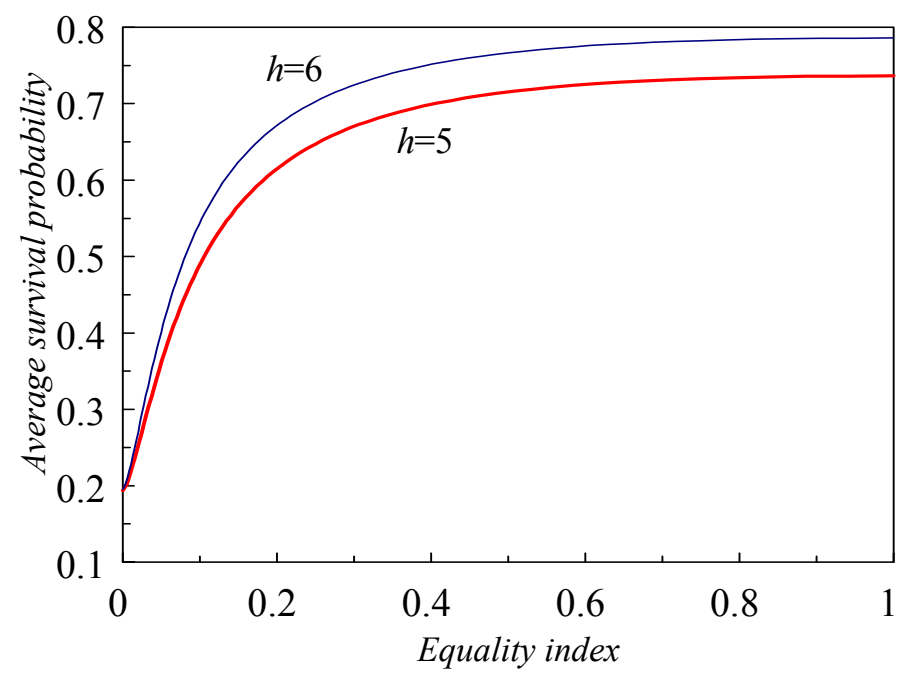

Figure 4: Average survival probability and human capital equality index $\left(h_{p t}^{t-1} / h_{r t}^{t-1}\right)$.

that the initial distribution of education matters a great deal for the evolution of the average human capital in the economy. It can be easily shown that, given two countries with the same average human capital stock in one period, the country with the greater inequality will exhibit lower average survival probability and, therefore, a lower stock of human capital in the following period. Assuming that the economy is populated by a fraction $\lambda=0.2$ of rich individuals, denoted by $r$, and a fraction $(1-\lambda)$ of poor individuals, denoted by $p$, in Figure 4 we have represented the average survival probability, for two economies with averages of 5 and 6 schooling years, as a function of the equality index $(e)$, that is constructed as the ratio between the human capital of poor and rich individuals

$$
e_{t}=\frac{h_{p, t}^{t-1}}{h_{r, t}^{t-1}}
$$

As we can observe, for an equality index higher than 0.4 the average survival probability increases very slowly, but when the index is below 0.4 , this probability decreases rapidly as the distribution of human capital becomes more unequal.

The empirical evidence supports this implication of the model. Using the calibrated function for the survival probability, we have estimated the following equation 
Table 1

Life expectancy and inequality

\begin{tabular}{lrr}
\hline \hline & \multicolumn{1}{c}{$(1)$} & \multicolumn{1}{c}{$(2)$} \\
\cline { 2 - 3 }$\theta_{\min }$ & 64.38 & 52.08 \\
& $(106.5)$ & $(21.2)$ \\
$\theta_{\max }$ & $64.38^{*}$ & 73.18 \\
& & $(43.9)$ \\
$\mu$ & -29.58 & -10.69 \\
& $(13.5)$ & $(2.72)$ \\
$d_{1}$ & - & -13.54 \\
& & $(8.60)$ \\
$d_{2}$ & - & 11.76 \\
& & $(6.11)$ \\
$R^{2}$ & 0.666 & 0.867 \\
Obs. & 92 & 92 \\
& &
\end{tabular}

t-ratios in parenthesis. * restricted parameter.

for a sample of 92 countries:

$$
L E_{i, 1985}=\theta_{\min }+\left(\theta_{\max }-\theta_{\min }\right) \pi_{i, 1985}\left(h_{i, 1960}\right)+\mu G h_{i, 1960}
$$

where $i$ refers to the different countries in the sample, the dependent variable is the life expectancy in 1985 (from the World Bank), $h$ is measured as the average years of schooling in 1960 (from Barro and Lee, 2001) and $G h$ is the Gini coefficient of human capital in 1960 taken from Castelló and Doménech (2002), in deviations from the sample average. The estimated value of $\theta_{\min }$ is the life expectancy of a country where $\pi_{i}\left(h_{i}\right)=0$ and the Gini coefficient is equal to the sample average. The equation also includes two dummy variables $d_{1}$ (Lesotho, Malawi, Senegal, Sierra Leone, Uganda and Bolivia ) and $d_{2}$ (Tunisia, Iraq, Kuwait and Portugal) which control for outliers, since their residuals exceed in more than two times the estimated standard error of the residuals. Since the endogenous variable is dated in 1985 and the regressors in 1960 we avoid possible endogeneity problems in this regression. The results of the estimation of equation (15) by OLS are presented in Table 1 . In column (1) we regress $L E$ on a constant and $G h$, which in equation (15) is equivalent to impose that $\theta_{\max }=\theta_{\min }$, whereas in column (2) we introduce $\pi$ as an additional regressor. In both specifications, the Gini coefficient of human capital has a negative and statistically significant effect on life expectancy, confirming the prediction of the model that, other things being equal, countries with a more 


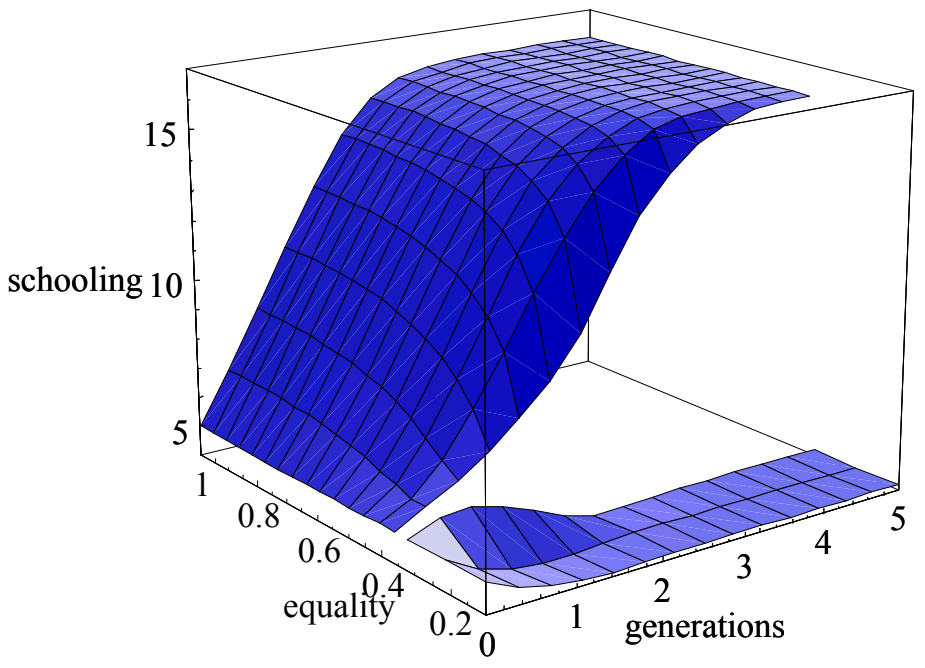

Figure 5: The dynamics of schooling years as a function of the initial distribution of human capital, characterized by the equality index.

unequal distribution of human capital will exhibit lower life expectancy. The results in Table 1 also show that the Gini coefficient and our calibrated function for the survival probability, both dated in 1960, explain a large variance (86.7 per cent) of life expectancy across countries.

As the distribution of human capital affects the average life expectancy of the economy, inequality will also have a negative effect on the steady state level of average schooling years and, therefore, on the growth rate of the economy during the transition to the steady state. In Figure 5 we have illustrated this implication of the model. Let us assume again that the economy is populated by a fraction $\lambda=0.2$ of rich individuals and a fraction $(1-\lambda)$ of poor individuals, such that the average human capital of the economy is given by

$$
\bar{h}_{t}=\lambda h_{r, t}^{t-1}+(1-\lambda) h_{p, t}^{t-1}
$$

For a starting level of schooling $\bar{h}_{t}$ there are different combinations $h_{r, t}^{t-1}$ and $h_{p, t}^{t-1}$ satisfying this condition, with important implications on the distribution of human capital. For example, if human capital is perfectly distributed then $h_{r, t}^{t-1}=h_{p, t}^{t-1}=\bar{h}_{t}$ and $e_{t}=1$. On the contrary, if the human capital of rich individuals is the high steady sate level, 
such that $h_{r, t}^{t-1}=16$, then

$$
h_{p, t}^{t-1}=\frac{\bar{h}_{t}-\lambda 16}{1-\lambda} .
$$

In Figure 5 we have assumed that $\bar{h}_{t}$ is equal to 5 years, above the unstable steady state, and we have simulated the dynamics of the average human capital, using equation (9) for the two groups of individuals and different initial distributions, which are characterized by the equality index. Given the calibrated values of the parameters, the steady state is reached after five generations or even less. Economies with a low inequality index reach a high steady state in which $h_{r, t+j}^{t+j-1}=h_{p, t+j}^{t+j-1}=16$ and the transition is more rapid the higher the equality in the initial distribution of human capital. In contrast, when $e_{t} \leq 0.34$ the average human capital reach very quickly a low steady state in which $h_{r, t+j}^{t+j-1}=16$ and $h_{p, t+j}^{t+j-1}=0$. Therefore, the distribution of human capital has outstanding effects upon the economic prospects of societies.

\section{Conclusions}

This paper has analyzed an alternative mechanism which explains why inequality in the distribution of income or wealth may be harmful for human capital accumulation. The underlying mechanism is based on the assumption that the life expectancy of individuals is somehow conditioned by the socioeconomic status of the family which they are born into. In particular, we have assumed that life expectancy is an increasing function of the human capital of the parents, an assumption strongly supported by the empirical evidence.

Based on this assumption the paper develops an overlapping generation model in which individuals live for sure during their first period of life and face an endogenous probability of surviving the whole second period. Given this probability, they choose the amount of time devoted to accumulating human capital that maximizes their intertemporal utility. As expected, the results show that the time individuals devote to schooling increases with their expected survival probability.

To analyze the relationship between inequality and growth we have simulated a life expectancy function according to the data of schooling years provided by Barro and Lee (2001). The empirical evidence shows a clear relationship between average schooling years across countries. Given the calibrated survival probability function, the model exhibits multiple steady states depending on initial conditions. Rich individuals, born into families whose parents have high levels of education, have high life expectancy. Their long life expectancy encourages them to spend a large number of years in education. On the contrary, individuals who are born into poor families have low life expectancy. 
Accordingly, since the time they expect to benefit from the returns to education is very short, they devote little time to accumulating human capital.

These results imply that the initial distribution of education determines the evolution of the aggregate variables in the model. In particular, the model also shows that inequality may have negative effects upon the growth rate of the economy during the transition to the steady state. The policy implications of the model suggest that governments could bring individuals out of the no schooling poverty trap if they guarantee a minimum compulsory level of education for some generations. Measures that, at the same time, would generate longer average life expectancy and higher standard of living in the less developed economies in the medium and long-term.

\section{Bibliography}

Aghion, P. and P. Bolton (1997): "A Theory of Trickle-Down Growth and Development". Review of Economic Studies, 64, 151-172.

Aghion, P., E. Caroli and C. García-Peñalosa (1999): "Inequality and Economic Growth: the Perspective of the New Growth Theories". Journal of Economic Literature, 37, 1615-1660.

Alesina, A. and D. Rodrik (1994): "Distributive Politics and Economic Growth". Quarterly Journal of Economics, 109, 465-490.

Azariadis C. (2001): "The Theory of Poverty Traps: What Have we Learned". Mimeo, UCLA.

Banerjee, A. V. and A. F. Newman (1993): "Occupational Choice and the Process of Development". Journal of Political Economy, 101(2), 274-298.

Barker, D. (1997): "Maternal Nutrition, Fetal Nutrition and Diseases in Later Life". Nutrition, 13(9), 807-813.

Barro, R. J. and J. W. Lee (2001): "International Data on Educational Attainment Updates and Implications". Oxford Economic Papers, 3, 541-63.

Benabou, R. (1996): "Inequality and Growth". NBER Working Paper 5658.

Bertola, G. (1993): "Factor Shares and Savings in Endogenous Growth". American Economic Review, 83, 1184-1199.

Blackburn K. and G. P. Cipriani (2002): "A Model of Longevity, Fertility and Growth". Journal of Economic Dynamics and Control, 26(2), 187-204.

Case, A. D. Lubotsky and Ch. Paxon (2001): "Economic Status and Health in Childhood: the Origins of the Gradient". American Economic Review, forthcoming.

Castelló, A. and R. Doménech (2002): "Human Capital Inequality and Economic Growth: Some New Evidence". Economic Journal, 112 (478), 187-200.

Currie, J. and R. Hyson (1999): "Is the Impact of Health Shocks Cushioned by Socioeconomic Status? The Case of Low Birthweight." American Economic Review, 89(2), 245-250.

De la Croix, D. and O. Licandro (1999): "Life Expectancy and Endogenous Growth". Economic Letters, 65, 255-263.

De la Fuente, A. and R. Doménech (2001): "Human Capital in Growth Regressions: How Much Difference Does Data Quality Make?". Economics Department Working Papers No. 262. OECD.

Deaton A. and Ch. Paxon (1999): "Mortality, Education, Income and Inequality among American 
Cohorts", NBER Working Paper 7140.

Ehrlich I. and F. T. Lui (1991): "Intergenerational Trade, Longevity, and Economic Growth". Journal of Political Economy, 99, 1029-1059.

Eicher, T. O. and C. García-Peñalosa (2001): "Inequality and Growth: the Dual Role of Human Capital in Development". Journal of Development Economics, 66, 173-197.

Galor, O. and J. Zeira (1993): "Income Distribution and Macroeconomics". Review of Economic Studies, 60, 35-52.

Kalemli-Ozcan, S. , H. E. Ryder and D. N. Weil (2000): "Mortality Decline, Human Capital Investment and Economic Growth". Journal of Development Economics, 62, 1-23.

Kalemli-Ozcan, D. (2001): "Does Mortality Decline Promote Economic Growth?". Mimeo, University of Houston.

Kremer, M., A. Onatski and J. Stock (2001): "Searching for Prosperity". NBER Working Paper, No. 8520.

Krueger, A. B. and M. Lindahl (2001): "Education for Growth: Why and for Whom?". Journal of Economic Literature, 39(4), 1101-1136.

Lleras-Muney, A. (2002): "The Relationship Between Education and Adult Mortality in the United States". NBER Working Paper 8986.

Marmot, M. G., G. D. Smith, S. Stansfeld, C. Patel, F. North, J. Head, I. White, E. Brunner and A. Feeney. (1991): "Health Inequality Among British Civil Servants: the Whitahall II Study". The Lancet, 337, 1387-1393.

Mincer, J. (1974): Schooling, Experience and Earnings. Columbia University Press.

Moav, O. (2001): "Cheap Children and the Persistence of Poverty". CEPR Discussion Paper Series, No. 3059.

Persson, T. and G. Tabellini (1994): "Is Inequality Harmful for Growth? Theory and Evidence". American Economic Review, 84, 600-621.

Piketty, T. (1997): "The Dynamics of the Wealth Distribution and the Interest Rate with Credit Rationing". Review of Economic Studies, 64, 173-189.

Quah, D. (1993a): "Empirical Cross-Section Dynamics in Economic Growth". European Economic Review, 37, 426-434.

Quah, D. (1993b): "Galton's Fallacy and Test of the Convergence Hypothesis". Scandinavian Journal of Economics 95(4), 427-443.

Quah, D. (1996): "Empirics for Economic Growth and Convergence". European Economic Review, 40, 1353-1375.

Ravelli, A., J. van der Meulen, R. Michels, C. Osmond, D. Barker, C. Hales and O. Bleker (1998): "Glucose Tolerance in Adults after Prenatal Exposure to Famine". The Lancet, 351, 173-177.

Smith, J. P. (1999): "Healthy Bodies and Thick Wallets: The Dual Relation Between Health and Economic Status". Journal of Economic Perspectives, 13, 145-166.

Smith, V. K., D. H. Taylor, Jr., and F. A. Sloan (2001): "Longevity Expectations and Death. Can People Predict Their Own Demise?". American Economic Review, 91, No. 4, 1126-1134.

Soares, R. R. (2001): "Life Expectancy, Education Attainment, and Fertility Choice". Mimeo, University of Chicago.

Tamura, R. (2002): "Human Capital and Economic Development". Working Paper No. 2002-5, Federal Reserve Bank of Atlanta.

Thomas, D, J. Strauss and M-H. Henriques (1990): "Child Survival, Height for Age and Household Characteristics in Brazil". Journal of Development Economics, 33, 197-234. 
Thomas, D, J. Strauss and M-H. Henriques (1991): "How does Mother's Education Affect Child Height?". Journal of Human Resources, 34(2), 183-211.

\section{Appendix 1}

The optimization problem for an individual $i$ is given by

$$
\underset{L_{i t}^{t}}{\operatorname{Max}} u_{i}^{t}=\ln c_{i t}^{t}+\gamma \pi_{i t+1}^{t}\left(h_{i t}^{t-1}\right) \ln c_{i t+1}^{t}
$$

subject to

$$
\begin{gathered}
c_{i t}^{t}=A L_{i t}^{t}+\beta A\left(1-L_{i t}^{t}\right) \\
c_{i t+1}^{t}=A \exp \left\{\alpha \theta\left(1-L_{i t}^{t}\right)\right\}-\frac{\beta A}{\pi_{i t+1}^{t}\left(h_{i t}^{t-1}\right)}\left(1-L_{i t}^{t}\right) \\
L_{i t}^{t} \geq 0 \\
L_{i t}^{t} \leq 1
\end{gathered}
$$

The Lagrange function for this problem is as follows:

$$
£=u_{i}^{t}\left(L_{i t}^{t}\right)+\mu\left(1-L_{i t}^{t}\right)
$$

Applying Kuhn-Tucker conditions for the inequality restriction, the first order conditions for this problem are:

$$
\begin{aligned}
\frac{\partial £}{\partial L_{i t}^{t}} \leq 0 ; & L_{i t}^{t} \geq 0 ; & L_{i t}^{t} \frac{\partial £}{\partial L_{i t}^{t}}=0 \\
\frac{\partial £}{\partial \mu} \geq 0 ; & \mu \geq 0 ; & \mu \frac{\partial £}{\partial \mu}=0
\end{aligned}
$$

The interior solution $\left(0<L_{i t}^{t}<1\right)$ implies that:

$$
\mu=0 \quad \text { and } \quad \frac{\partial u_{i}^{t}}{\partial L_{i t}^{t}}=0
$$


or

$$
\frac{1}{c_{i t}^{t}} A(1-\beta)=\frac{\gamma \pi_{i t+1}^{t}\left(h_{i t}^{t-1}\right)}{c_{i t+1}^{t}}\left[\alpha \theta A \exp \left\{\alpha \theta\left(1-L_{i t}^{t}\right)\right\}-\frac{\beta}{\pi_{i t+1}^{t}\left(h_{i t}^{t-1}\right)} A\right]
$$

Substituting $c_{i t}^{t}$ and $c_{i t+1}^{t}$, using (A1.2) and (A1.3) we get

$$
\begin{aligned}
& (1-\beta)\left(\exp \left\{\alpha \theta\left(1-L_{i t}^{t}\right)\right\}-\frac{\beta}{\pi_{i t+1}^{t}\left(h_{i t}^{t-1}\right)}\left(1-L_{i t}^{t}\right)\right)=\gamma \pi_{i t+1}^{t}\left(h_{i t}^{t-1}\right) \\
& \left(\alpha \theta \exp \left\{\alpha \theta\left(1-L_{i t}^{t}\right)\right\}-\frac{\beta}{\pi_{i t+1}^{t}\left(h_{i t}^{t-1}\right)}\right)\left(L_{i t}^{t}+\beta\left(1-L_{i t}^{t}\right)\right)
\end{aligned}
$$

where $L_{i t}^{t}$ is a decreasing function of the expected survival probability.

\section{Appendix 2}

Given the values of the parameters for the survival probability function, discussed in subsection 3.1, when $h_{i t}^{t-1}=0$ then $\pi_{i t+1}^{t}\left(h_{i t}^{t-1}\right)=0$, that is, when parents have no education, offsprings only live during the first period. In such a case individuals face the following optimization problem:

$$
\underset{L_{i t}^{t}}{\operatorname{Max}} u_{i}^{t}=\ln c_{i t}^{t}
$$

subject to

$$
\begin{gathered}
c_{i t}^{t}=A L_{i t}^{t} \\
0 \leq L_{i t}^{t} \leq 1
\end{gathered}
$$

If $L_{i t}^{t}$ were not restricted, the optimal value for $L_{i t}^{t}$ would tend to infinity. However, the restrictions make the optimal value to take the corner solution in which $L_{i t}^{t}=1$. This means that individuals who do not live in the second period do not accumulate human capital and devote all their time to work in order to maximize their first period consumption. The same restriction $L_{i t}^{t}=1$ applies when $h_{i t}^{t-1}$ is below the threshold level for which it is not optimal to devote time to education. 